\title{
THE CHARACTERISTIC OF DEFORMABILITY AND QUANTITATIVE DESCRIPTION OF THE MICROSTRUCTURE OF HOT-DEFORMED Ni-Fe SUPERALLOY
}

\begin{abstract}
The paper presents the results of research concerning the influence of hot plastic working parameters on the deformability and microstructure of a Ni-Fe superalloy. The research was performed on a torsion plastometer in the range of temperatures of $900-1150^{\circ} \mathrm{C}$, at a strain rates 0.1 and $1.0 \mathrm{~s}^{-1}$. Plastic properties of the alloy were characterized by the worked out flow curves and the temperature relationships of flow stress and strain limit. The structural inspections were performed on microsections taken from plastometric samples after so-called "freezing". The stereological parameters as the recrystallized grain size, inhomogenity and grain shape have been determined. Functional relations between the Zener-Hollomon parameter and the maximum yield stress and the average grain area have been developed and the activation energy for hot working has been estimated.

Keywords: Incolloy 718, hot deformation, recrystallization, quantitative metallography, Zener-Hollomon parameter
\end{abstract}

\section{Introduction}

The behavior of metals and alloys during hot plastic working has a complex nature and it varies with the changing of such process parameters as [1-5]: deformation, strain rate and temperature. The high-temperature plastic deformation is coupled with dynamic recovery and recrystallization processes which influencing the structure and properties of alloys. One of crucial issues is finding the relationship between the hot plastic deformation process parameters, microstructure and properties for steels and nickel alloys.

The Ni-Fe superalloys precipitation hardened by intermetallic phases of $\gamma^{\prime}-\mathrm{Ni}_{3}(\mathrm{Al}, \mathrm{Ti})$ and $\gamma^{\prime \prime}\left(\mathrm{Ni}_{3} \mathrm{Nb}\right)$ types are one of the groups of construction materials intended for operation in elevated and cryogenic temperatures. These alloys are difficult to deform and are characterized by high values of yield stress at a high temperature. High deformation resistance of Ni-Fe alloys is caused by a complex phase composition, high activation energy for hot working and a low rate of dynamic recrystallization. When choosing the conditions for hot plastic working of $\mathrm{Ni}-\mathrm{Fe}$ alloys, the following factors should be considered [6-10]: the matrix grain size, plastic deformation parameters and the course of the recrystallization process. The grain size is particular importance. Grain refining leads to an increased rate of recovery and dynamic recrystallization and to a smaller diameter of recrystallized grains. This is important, for the grain refinement in a Ni-Fe superalloys has an advantageous influence on increasing their yield point and fatigue strength $[11,12]$.

In the presented study, research has been undertaken on the influence of the parameters of hot plastic working on deformability and microstructure in a Ni-Fe superalloy. It is assumed that the results obtained will be used for optimizing hot plastic working processes and forecasting the microstructure and functional properties of products made of $\mathrm{Ni}-\mathrm{Fe}$ superalloys.

\section{Material and experimental procedure}

The examinations were performed on rolled bars, $16 \mathrm{~mm}$ in diameter, of an Incolloy 718 type superalloy. The chemical composition is given in (Table 1).

In order to model the conditions of alloy heating prior to plastic processing, the investigations were carried out on samples after initial soaking at high temperature. The samples

TABLE 1

Chemical composition of the investigated Ni-Fe superalloy

\begin{tabular}{|c|c|c|c|c|c|c|c|c|c|c|c|c|c|c|}
\hline \multicolumn{15}{|c|}{ Content of an element, wt. \% } \\
\hline $\mathbf{C}$ & $\mathbf{S i}$ & Mn & $\mathbf{P}$ & $\mathbf{S}$ & $\mathbf{C r}$ & $\mathbf{N i}$ & Mo & Co & Al & $\mathbf{C u}$ & $\mathbf{N b}$ & Ti & $\mathbf{B}$ & $\mathbf{F e}$ \\
\hline 0.04 & 0.16 & 0.08 & 0.007 & 0.002 & 18.5 & 52.1 & 3.05 & 0.24 & 0.54 & 0.03 & 4.89 & 0.91 & 0.001 & 19.45 \\
\hline
\end{tabular}

\footnotetext{
SILESIAN UNIVERSITY OF TECHNOLOGY, FACULTY OF MATERIALS ENGINEERING AND METALLURGY, 8 KRASIŃSKIEGO STR., 40-019 KATOWICE, POLAND.

\# Corresponding author: kazimierz.ducki@polsl.pl
} 
for investigations were made from rolled bars sections which were subjected to preheating, i.e. $1120^{\circ} \mathrm{C} / 2 \mathrm{~h}$ with subsequent cooling in water. Heat treatment of this type corresponds to the soaking parameters of the investigated superalloy before hot plastic processing $[13,14]$.

The research on the alloy deformability was performed in a hot torsion test on a Setaram torsion plastometer $7 \mathrm{MNG}$. The plastometric tests were performed every $50^{\circ} \mathrm{C}$ in a temperature range of $900-1150^{\circ} \mathrm{C}$, with a constant holding time of $10 \mathrm{~min}-$ utes at the defined temperature. Solid cylindrical specimens $(\varnothing 6.0 \times 50 \mathrm{~mm})$ were twisted at a rotational speed of 50 and $500 \mathrm{rpm}$, which corresponds to the strain rate of 0.1 and $1.0 \mathrm{~s}^{-1}$, respectively. To freeze the structure, the specimens after deformation until failure were directly cooled in water.

From the data recorded, dependencies were determined of the yield stress $\left(\sigma_{p}\right)$ as a function of substitute strain $(\varepsilon)$, according to the methodology presented in papers [15-17]. On the flow curves determined, the following parameters characterizing plastic properties of the alloy in the torsion test were defined:

- $\sigma_{p p}$ - maximum yield stress on the flow curve;

$-\varepsilon_{p}-$ deformation corresponding to the maximum yield stress;

- $\sigma_{f}$ - stress at which the sample is subject to failure;

$-\varepsilon_{f}-$ deformation at which the sample is subject to failure, the so-called strain limit.

Relations between the yield stress and alloy deformation, and the deformation conditions were described using the ZenerHollomon parameter $Z$ [18]:

$$
Z=\dot{\varepsilon} \times \exp \left(\frac{Q}{R T}\right)=A \times\left[\sinh \left(\alpha \sigma_{p_{\max }}\right)\right]^{n}
$$

where: $\dot{\varepsilon}$ - strain rate, $Q$ - activation energy for hot working, $R$ - molar gas constant, $T$ - temperature, and $A, \alpha, n$ - constants depending on grade of the investigated material.

The activation energy for hot working $Q$ was determined in accordance with the procedure specified in the work by Schindler and Bořuta [15]. The solution algorithm consisted in transforming (Eq. 1) to the following form:

$$
\dot{\varepsilon}=A \times \exp \left(\frac{-Q}{R T}\right)\left[\sinh \left(\alpha \sigma_{p_{\max }}\right)\right]^{n}
$$

Further procedure was based on solving (Eq. 2) by a graphic method with the application of a regression analysis.

Structural inspections were performed on longitudinal microsections taken from the plastically deformed samples until failure after so-called "freezing". The specimens were etched using a reagent with the following composition: $50 \mathrm{~cm}^{3}$ of hydrogen peroxide $\left(\mathrm{H}_{2} \mathrm{O}_{2}\right), 45 \mathrm{~cm}^{3}$ of hydrochloric acid $(\mathrm{HCl}), 5 \mathrm{~cm}^{3}$ of hydrofluoric acid (HF). Due to the deformation inhomogeneity, microscopic observation was conducted in a representative region located at a distance of ca. $0.65 \div 0.75$ of the specimen radius.

A quantitative analysis of the investigated microstructures was carried out by means of a computer program MET-ILO v. 3.0
[19]. For the analyzed microstructures, in accordance with the methodology presented in paper [20], the following stereological parameters were determined:

- $\quad$ average area of grain plane section $\bar{A}, \mu \mathrm{m}^{2}$;

- $\quad$ variability coefficient of the grain plane section area $v(\bar{A})$;

- volume fraction of dynamically recrystallized grains in the structure $V_{V}, \%$;

- $\quad$ grain elongation coefficient $\delta$ (Feret coefficient);

- classical, dimensionless shape coefficient $\xi$.

\section{Results and discussions}

The results of the plastometric investigations, in the form of the calculated alloy flow curves at temperatures of $900-1150^{\circ} \mathrm{C}$ for two strain rates, are shown in (Figs. 1,2). The curves obtained for the strain rate of $0.1 \mathrm{~s}^{-1}$ have a shape characteristic of a material in which dynamic recovery and recrystallization take place (Fig. 1). High deformation values $\left(\varepsilon_{f}=2.4 \div 3.2\right)$ were obtained for the alloy in a wide range of torsion temperature, i.e. $1000-1100^{\circ} \mathrm{C}$.

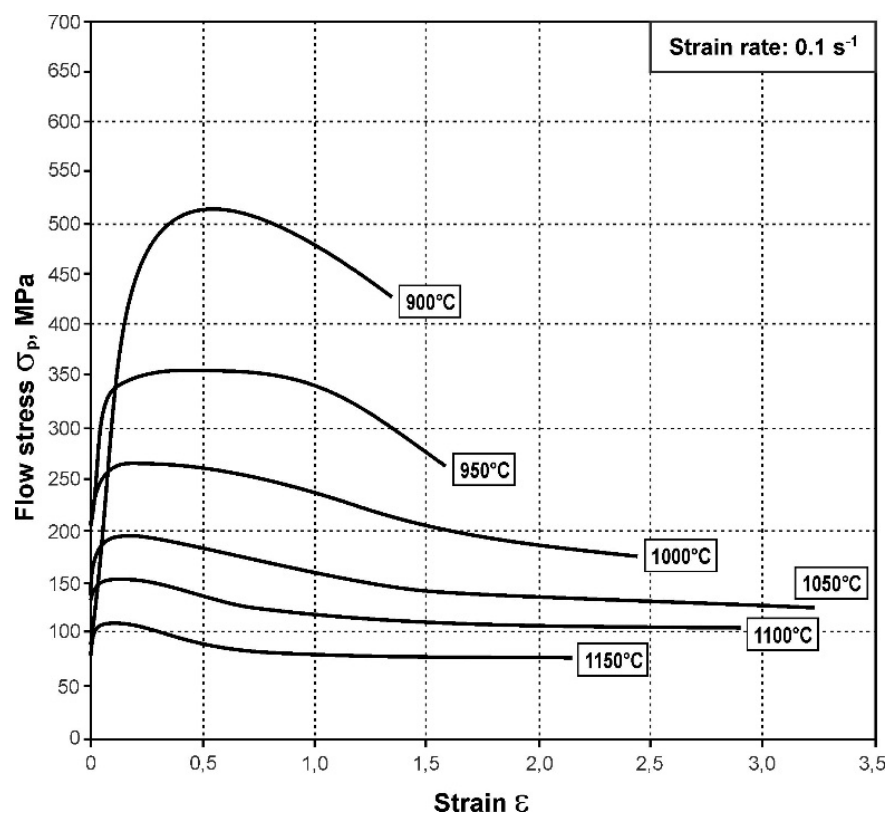

Fig. 1. The effect of deformation temperature on the flow stress of $\mathrm{Ni}-\mathrm{Fe}$ superalloy after initial soaking at $1120^{\circ} \mathrm{C} / 2 \mathrm{~h}$. Strain rate: $0.1 \mathrm{~s}^{-1}$

An increase of the strain rate up to $1.0 \mathrm{~s}^{-1}$ significantly increases the yield stress values and clearly decreases the alloy deformability at all the examined temperatures (Fig. 2). This phenomenon can be explained by a higher alloy consolidation rate as well as too slow removal of the strengthening as a result of dynamic recovery and recrystallization. The highest values of deformation until failure were lower $\left(\varepsilon_{f}=1.2 \div 1.5\right)$ and they were obtained for the alloy in a narrow range of torsion temperatures, i.e. $1050-1100^{\circ} \mathrm{C}$.

The values determined for the maximum yield stress $\sigma_{p p}$ and strain limit $\varepsilon_{f}$ depending on the temperature and strain rate 


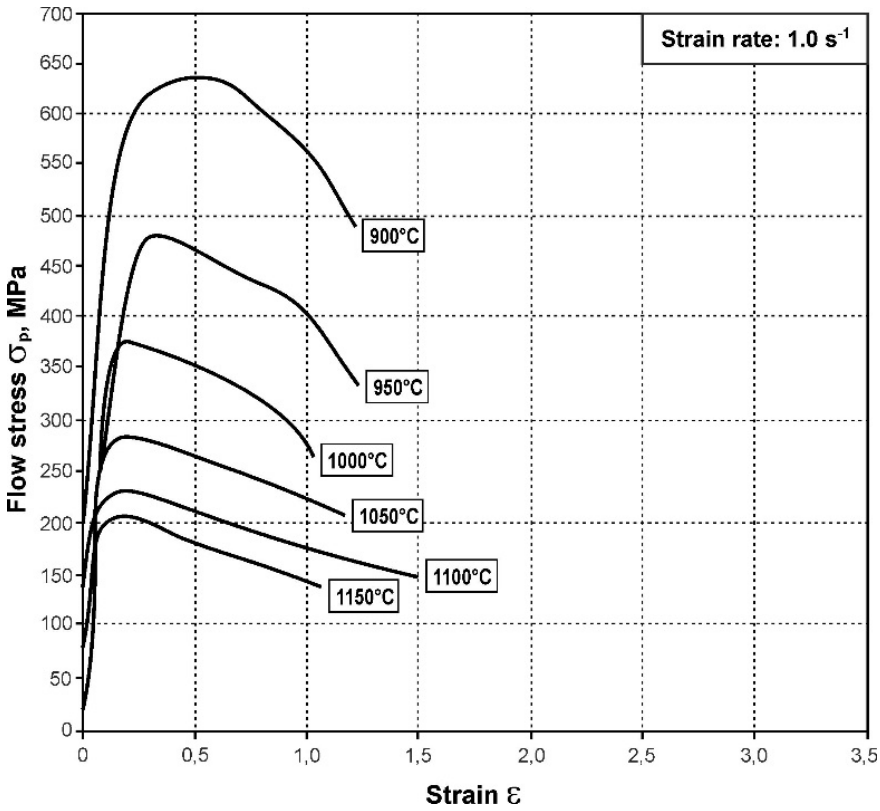

Fig. 2. The effect of deformation temperature on the flow stress of $\mathrm{Ni}-\mathrm{Fe}$ superalloy after initial soaking at $1120^{\circ} \mathrm{C} / 2 \mathrm{~h}$. Strain rate: $1.0 \mathrm{~s}^{-1}$

are presented in (Table 2) and (Figs. 3,4). For the option of initial soaking at $1120^{\circ} \mathrm{C} / 2 \mathrm{~h}$ and strain rate of $0.1 \mathrm{~s}^{-1}$, the alloy under discussion shows a continuous drop of $\sigma_{p p}$ from values $514 \mathrm{MPa}$ at a temperature of $900^{\circ} \mathrm{C}$ to the value of $113 \mathrm{MPa}$ at $1150^{\circ} \mathrm{C}$ (Fig. 3). The strain limit $\varepsilon_{f}$ rises initially together with the torsion temperature, reaching the maximum of (3.25/2.91) at $1050-1100^{\circ} \mathrm{C}$, and then falls (Fig. 4). An increase of the strain rate to $1.0 \mathrm{~s}^{-1}$ results in an increase of $\sigma_{p p}$ to maximum values of $636 \mathrm{MPa}$ at the temperature of $900^{\circ} \mathrm{C}$ (Fig. 3) and a decrease of the strain limit to the maximum of $1.15 / 1.43$ at $1000-1050^{\circ} \mathrm{C}$ (Fig. 4).

TABLE 2

The index of the Ni-Fe alloy plastic properties determine from flow curves

\begin{tabular}{|c|c|c|c|c|c|}
\hline \hline \multicolumn{2}{|c|}{$\begin{array}{c}\text { Deformation } \\
\text { parameters }\end{array}$} & \multicolumn{4}{|c|}{ Plastic properties } \\
\hline $\boldsymbol{T},{ }^{\circ} \mathbf{C}$ & $\dot{\boldsymbol{\varepsilon}} \mathbf{s}^{\mathbf{- 1}}$ & $\sigma_{p p}, \mathbf{M P a}$ & $\boldsymbol{\varepsilon}_{\boldsymbol{p}}$ & $\sigma_{f}, \mathbf{M P a}$ & $\boldsymbol{\varepsilon}_{\boldsymbol{f}}$ \\
\hline 900 & 0.1 & 514 & 0.48 & 429 & 1.35 \\
\hline 950 & 0.1 & 358 & 0.43 & 265 & 1.58 \\
\hline 1000 & 0.1 & 266 & 0.22 & 177 & 2.44 \\
\hline 1050 & 0.1 & 198 & 0.21 & 127 & 3.25 \\
\hline 1100 & 0.1 & 157 & 0.10 & 104 & 2.91 \\
\hline 1150 & 0.1 & 113 & 0.10 & 78 & 2.14 \\
\hline 900 & 1.0 & 636 & 0.48 & 486 & 1.22 \\
\hline 950 & 1.0 & 482 & 0.36 & 334 & 1.23 \\
\hline 1000 & 1.0 & 381 & 0.21 & 258 & 1.05 \\
\hline 1050 & 1.0 & 288 & 0.21 & 208 & 1.15 \\
\hline 1100 & 1.0 & 233 & 0.24 & 150 & 1.43 \\
\hline 1150 & 1.0 & 209 & 0.21 & 138 & 1.05 \\
\hline
\end{tabular}

The activation energy for hot working $Q$ was calculated by the means of a computer programme ENERGY 3.0 [15].

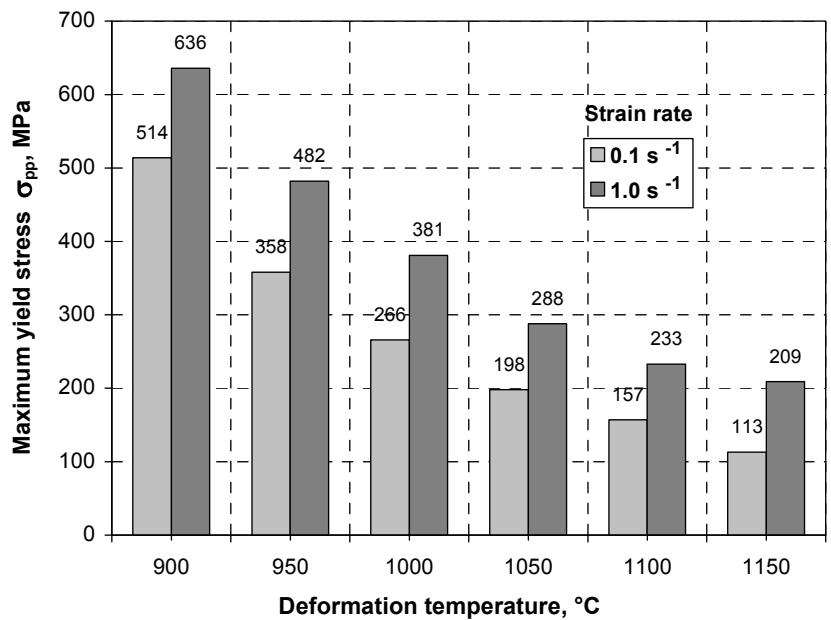

Fig. 3. The effect of deformation conditions on maximum flow stress of the alloy

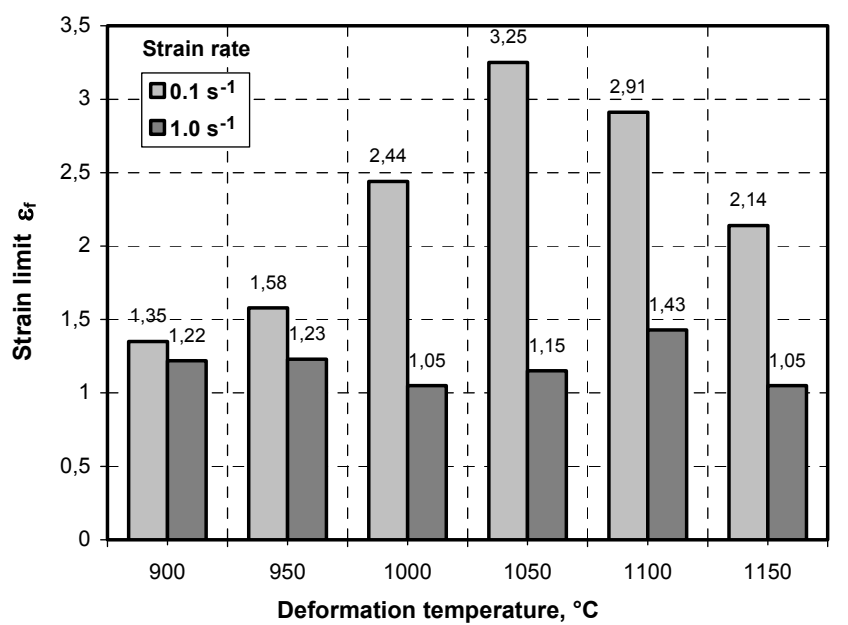

Fig. 4. The effect of deformation conditions on strain limit of the alloy

The estimated activation energy for hot working in the range of the applied deformation temperatures of $900-1150^{\circ} \mathrm{C}$ and strain rates of 0.1 and $1.0 \mathrm{~s}^{-1}$, was high and amounted $Q=482 \mathrm{~kJ} / \mathrm{mol}$.

The dependence between maximum yield stress $\sigma_{p p}$ and Zener Hollomon parameter $Z$ is presented in (Fig. 5). For analyzed option of initial soaking, a power dependence $\left(R^{2}=0.99\right)$ of the alloy yield stress was obtained as a function of the $Z$ parameter. So determined function dependence between the maximum yield stress $\sigma_{p p}$ and the $Z$ parameter had a form of power function:

$$
\sigma_{p p}=0.35 \cdot Z^{0.15}, \mathrm{MPa}
$$

The results of investigations of the alloy microstructure after the deformation in a temperature range $900-1150^{\circ} \mathrm{C}$ and a strain rates of 0.1 and $1.0 \mathrm{~s}^{-1}$ are presented in (Figs. 6a-d). After deformation at $900^{\circ} \mathrm{C}$ for both of the torsion rates applied, the alloy structure is not completely recrystallized, which is indicated by the presence of primary elongated grains and fine recrystallized grains (Fig. 6a). At a torsion temperature in the range of $950-1100^{\circ} \mathrm{C}$, the alloy structure consisted of dynamically recrystallized grains (Figs. 6b,c). With an increasing deformation temperature, a gradual growth of the recrystallized grains 


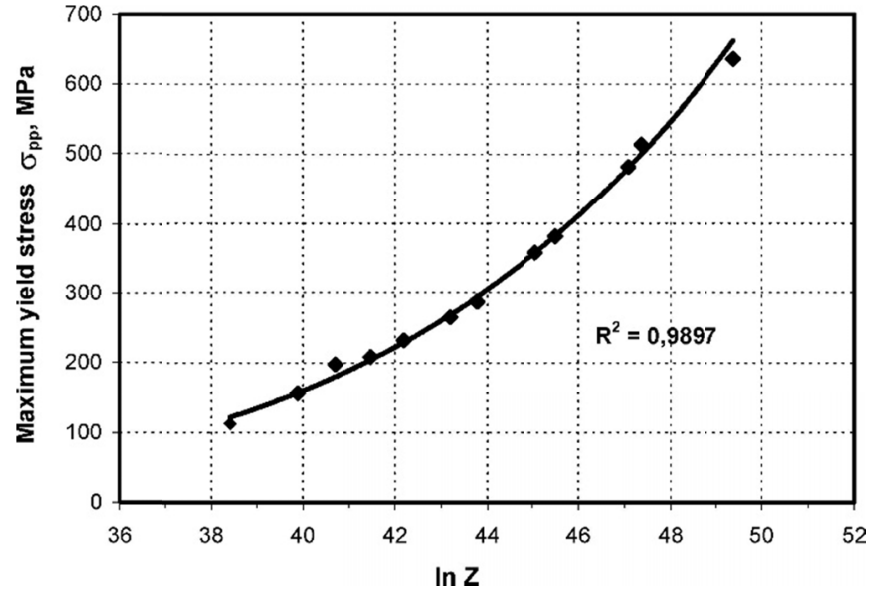

Fig. 5. Dependence of the maximum yield stress on the Zener-Hollomon parameter $Z$

was observed. The recrystallized grains were characterized by a deformed grain boundary line, which indicates an extensive cumulated deformation in the specimens. At the highest torsion temperature, $1150^{\circ} \mathrm{C}$, some elongated grains of dynamically recrystallized austenite are observed in the alloy structure (Fig. 6d).

The results of a quantitative evaluation of the investigated alloy microstructure after deformation until failure in a temperature range of $900-1150^{\circ} \mathrm{C}$ and a strain rates of 0.1 and $1.0 \mathrm{~s}^{-1}$ are presented in (Table 3) and in (Figs. 7,8).

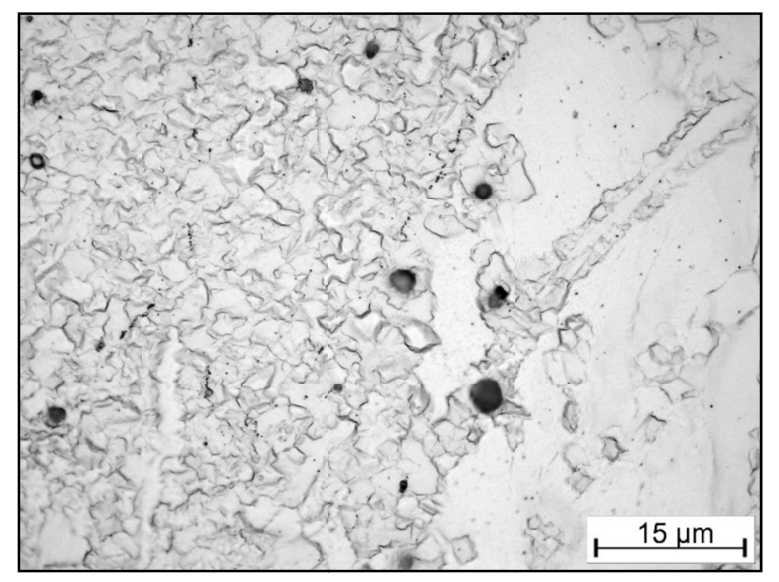

a)

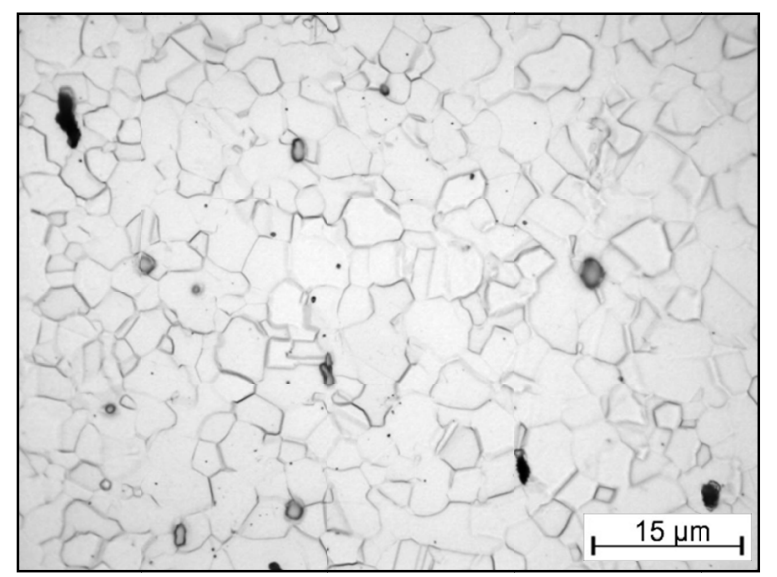

c)
TABLE 3

Stereological parameters of the alloy microstructure after deformation in a temperature range of $900-1150^{\circ} \mathrm{C}$ at a strain rates of 0.1 and $1.0 \mathrm{~s}^{-1}$

\begin{tabular}{|c|c|c|c|c|c|c|c|c|}
\hline \multicolumn{2}{|c|}{$\begin{array}{l}\text { Deforma- } \\
\text { tion } \\
\text { parameters }\end{array}$} & \multirow{2}{*}{$\begin{array}{c}\text { Volume } \\
\text { fraction of } \\
\text { recrystallized } \\
\text { grains } \\
V_{V}, \\
\%\end{array}$} & \multicolumn{2}{|c|}{$\begin{array}{c}\text { Grain } \\
\text { average } \\
\text { area }\end{array}$} & \multicolumn{2}{|c|}{$\begin{array}{c}\text { Grain } \\
\text { elongation } \\
\text { coefficient }\end{array}$} & \multicolumn{2}{|c|}{$\begin{array}{c}\text { Dimen- } \\
\text { sionless } \\
\text { shape } \\
\text { coefficient }\end{array}$} \\
\hline $\begin{array}{l}\mathrm{T}, \\
{ }^{\circ} \mathbf{C}\end{array}$ & $\begin{array}{c}\dot{\varepsilon} \\
\mathrm{s}^{-1}\end{array}$ & & $\begin{array}{c}\bar{A}, \\
\mu \mathbf{m}^{2}\end{array}$ & $\begin{array}{c}v(A), \\
\%\end{array}$ & $\delta$ & $\begin{array}{c}v(\delta), \\
\%\end{array}$ & $\xi$ & $\begin{array}{c}v(\xi), \\
\%\end{array}$ \\
\hline 900 & 0.1 & 100 & 4.3 & 174 & 1.65 & 32 & 0.68 & 23 \\
\hline 950 & 0.1 & 100 & 6.2 & 176 & 1.69 & 32 & 0.69 & 24 \\
\hline 1000 & 0.1 & 100 & 19.5 & 180 & 1.68 & 29 & 0.81 & 21 \\
\hline 1050 & 0.1 & 100 & 36.5 & 123 & 1.70 & 30 & 0.78 & 23 \\
\hline 1100 & 0.1 & 100 & 78.2 & 90 & 1.69 & 30 & 0.69 & 28 \\
\hline 1150 & 0.1 & 100 & 204.7 & 82 & 1.85 & 59 & 0.70 & 21 \\
\hline 900 & 1.0 & 59 & 21.4* & 288 & 1.64 & 24 & 0.79 & 21 \\
\hline 950 & 1.0 & 100 & 49.2 & 97 & 1.69 & 39 & 0.76 & 20 \\
\hline 1000 & 1.0 & 100 & 65.4 & 94 & 1.68 & 30 & 0.76 & 21 \\
\hline 1050 & 1.0 & 100 & 91.0 & 95 & 1.79 & 52 & 0.75 & 19 \\
\hline 1100 & 1.0 & 100 & 141.5 & 109 & 1.82 & 43 & 0.71 & 21 \\
\hline 1150 & 1.0 & 100 & 207.4 & 110 & 1.85 & 50 & 0.70 & 20 \\
\hline
\end{tabular}

In the microstructure of the alloy after deformation in the investigated temperature range at a strain rate equal $0.1 \mathrm{~s}^{-1}$, monotonous growth of the grain average area $\bar{A}$ is observed

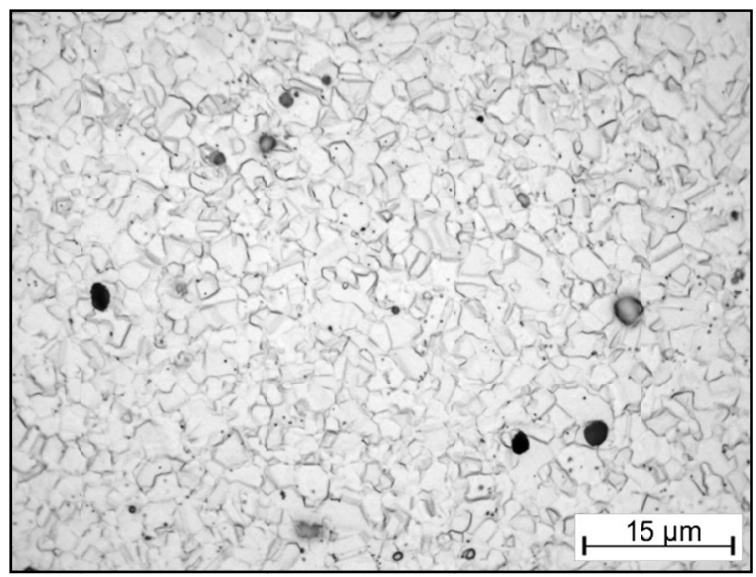

b)

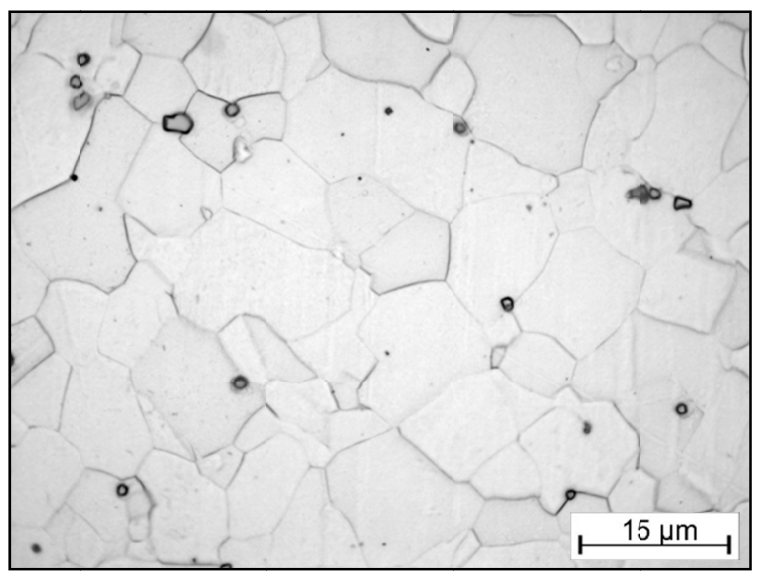

d)

Fig. 6. The microstructure of the alloy after plastic deformation at: a) $900^{\circ} \mathrm{C} / 1.0 \mathrm{~s}^{-1}$, b) $1000^{\circ} \mathrm{C} / 0.1 \mathrm{~s}^{-1}$, c) $1100^{\circ} \mathrm{C} / 0.1 \mathrm{~s}^{-1}$, d) $1150^{\circ} \mathrm{C} / 1.0 \mathrm{~s}^{-1}$ 


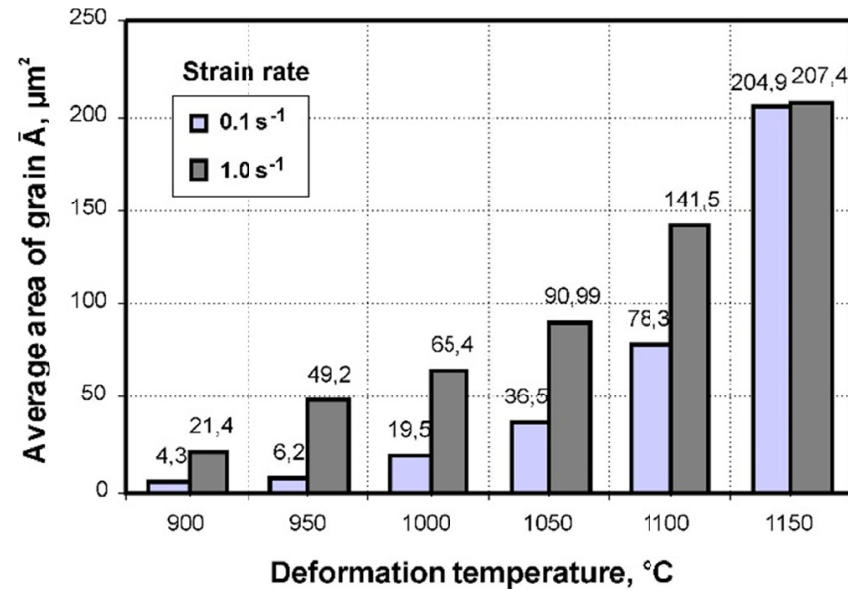

Fig. 7. The effect of deformation temperature on the average area of recrystallized grain after torsion at a strain rates of 0.1 and $1.0 \mathrm{~s}^{-1}$

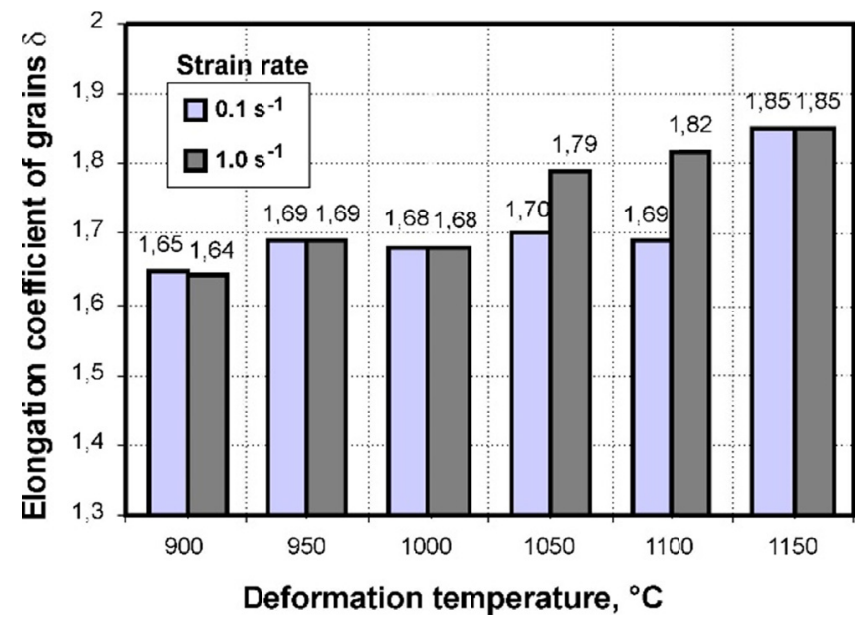

Fig. 8. The effect of deformation temperature on the elongation coefficient of recrystallized grain after torsion at a strain rates of 0.1 and $1.0 \mathrm{~s}^{-1}$

from a value $4.3 \mu \mathrm{m}^{2}$ at $900^{\circ} \mathrm{C}$ to $204.9 \mu \mathrm{m}^{2}$ at $1150^{\circ} \mathrm{C}$ (Fig. 7). Up to the deformation temperature of $1150^{\circ} \mathrm{C}$, the dynamically recrystallized grains are elongated $(\delta=1.65 \div 1.85)$ (Fig. 8$)$. An increase of the strain rate up to $1.0 \mathrm{~s}^{-1}$ induces a clear growth of the recrystallized grain size. Also, in this case, in the investigated range of deformation temperatures, a monotonous growth of the grain average area $\bar{A}$ was observed, from $21.4 \mu \mathrm{m}^{2}$ at $900^{\circ} \mathrm{C}$ to $207.4 \mu \mathrm{m}^{2}$ at $1150^{\circ} \mathrm{C}$ (Fig. 7). In the analyzed range of torsion temperatures of $900-1150^{\circ} \mathrm{C}$, the dynamically recrystallized grains are also elongated $(\delta=1.64 \div 1.85)$ (Fig. 8). Based on the obtained results, should be noted that higher strain rate provide shorter time for the energy accumulation and lower mobility boundaries which contribute in the nucleation and growth of dynamically recrystallized grains. For this reason with deformation at strain rate of $0.1 \mathrm{~s}^{-1}$ more and more potential nuclei are activated and new recrystalized grains appear, which are smaller than grains obtained during deformation at $1.0 \mathrm{~s}^{-1}$.

The dependencies between the average area of the recrystallized grains and the alloy deformation parameters are shown in (Fig. 9). For both of the strain rates applied, mathematical dependencies of an exponential nature were obtained. The cor- relation coefficient value was high and was contained in the range between 0.97 and 0.99 .

The functional dependence between the average grain area and the Zener-Hollomon parameter $Z$ is presented in (Fig. 10). For the analyzed alloy deformation parameters, a mathematical dependence of an involutory nature was determined:

$$
\bar{A}=1.77 \times 10^{6} \times Z^{-0.243}, \mathrm{~mm}^{2}
$$

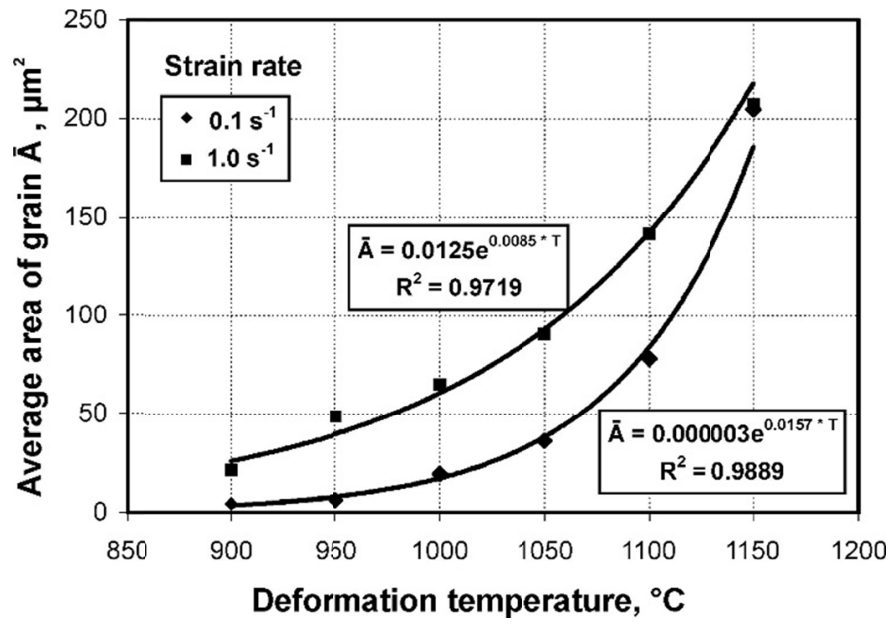

Fig. 9. Relationship between the average grain area after recrystallization versus deformation temperature and strain rates

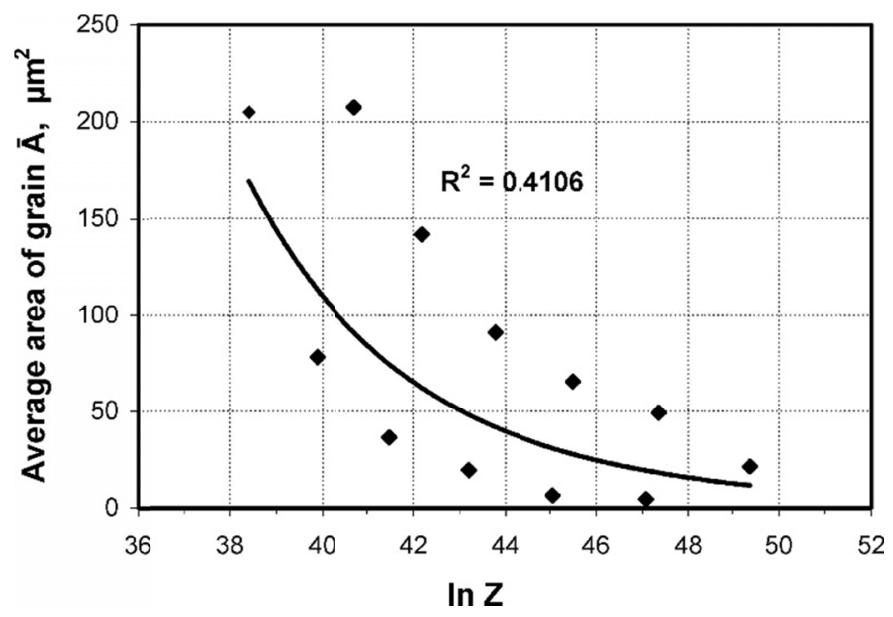

Fig. 10. Relationship between the average grain area after recrystallization and the Zener-Hollomon parameter $Z$

Functional relationship $\left(R^{2}=0.41\right)$ between the average grain area and the Zener-Hollomon parameter $Z$ for the analyzed deformation conditions was shown to be poor. The obtained curve shows a general decreasing tendency in average grain area with the increase of the parameter $Z$.

\section{Conclusions}

The performed examinations on a torsion plastometer in the range of temperatures of $900-1150^{\circ} \mathrm{C}$ and strain rates of 0.1 
and $1.0 \mathrm{~s}^{-1}$, indicated that the deformability and microstructure of the Ni-Fe superalloy depend considerably on parameters of the hot plastic deformation.

Optimum values of yield stress and strain limit were obtained for the alloy after the initial soaking at $1120^{\circ} \mathrm{C} / 2 \mathrm{~h}$ and deformation in the temperature range of $1100-1000^{\circ} \mathrm{C}$ at strain rate $0.1 \mathrm{~s}^{-1}$.

The dependence between the maximum yield stress $\sigma_{p p}$ and Zener-Hollomon parameter $Z$ has been described by means of a power function in the following form: $\sigma_{p p}=0.35 \cdot Z^{0.15}$. The estimated value of the activation energy for hot working was high and amounted $Q=482 \mathrm{~kJ} / \mathrm{mol}$.

A considerable influence has been found of the deformation temperature and strain rate on grain size and inhomogenity of the grain size after dynamic recrystallization. It was found that with an increasing deformation temperature and strain rate, a gradual growth of the recrystallized grains was observed. However, no explicit influence of the alloy deformation parameters on the shape of recrystallized grains has been observed.

It should be noted that higher strain rate provide shorter time for the energy accumulation and lower mobility boundaries which contribute in the nucleation and growth of dynamically recrystallized grains. For this reason alloy deformation at strain rate of $0.1 \mathrm{~s}^{-1}$ has a smaller grains after recrystallization in comparison to grains obtained during deformation at $1.0 \mathrm{~s}^{-1}$.

The functional dependence between the average grain area $\bar{A}$ and the Zener-Hollomon parameter $Z$ has been described by an involutory function in the following form: $\bar{A}=1.77 \times 10^{6} \times Z^{-0.243}$.

\section{REFERENCES}

[1] L.X. Zhou, T.N. Baker, Mater. Sci. Eng. A 177, 1-9 (1994).

[2] H.J. McQueen, N.D. Ryan, Mater Sci. Eng. A 322, 43-63 (2002).

[3] K.J. Ducki, K. Rodak, M. Hetmańczyk, D. Kuc, Mater. Chem. Phys. 81, 493-495 (2003).
[4] K.J. Ducki, M. Hetmańczyk, D. Kuc, Mater. Sci. Forum 513, 5159 (2006).

[5] K.J. Ducki, K. Rodak, IOP Conf. Series-Mater. Sci. Eng. 22, 012011 (2011).

[6] R. Srinivasan, Y.V. Prasad, Metall. Mater. Trans. A 25A, 22752284 (1994).

[7] S.C. Medeiros, Y.V. Prasad, W.G. Frazier, R. Srinivasan, Mater. Sci. Eng. A 293, 198-207 (2000).

[8] C. Bruni, A. Forcellese, F. Gabrielli, J. Mater. Process. Tech. 125126, 242-247 (2002).

[9] K.J. Ducki, J. Mendala, L. Wojtynek, Solid State Phenom. 212, 15-20 (2014).

[10] L. Pająk, K.J. Ducki, L.Wojtynek, Solid State Phenom. 212, 225228 (2014).

[11] A.K. Koul, J.P. Immarigeon, W. Wallace, Advanced in high temperature structural materials and protective coatings, National Research Council of Canada, Ottawa, 95-125 (1994).

[12] G. Härkegård, J.Y. Guédou, Proc. of the $6^{\text {th }}$ Conference, Materials for Advanced Power Engineering, Liége, 913-931 (1998).

[13] N.S. Stoloff, ASM Handbook 1. Properties and Selection Irons, Steels and High-Performance Alloys, ASM Materials Information Society, 950-977 (1990).

[14] N.K. Park, I.S. Kim, Y.S. Na, J.T. Yeom, J. Mater. Process. Tech. 111, 98-102 (2001).

[15] I. Schindler, J. Bořuta, Utilization Potentialities of the Torsion Plastometer, Department of Metal Forming, Silesian University of Technology, Katowice (1998).

[16] E. Hadasik, I. Schindler, Plasticity of metallic materials, Silesian University of Technology, House of Publishing, Gliwice (2004).

[17] E. Hadasik, Arch. Metall. Mater. 50 (3), 729-746 (2005).

[18] C.M. Sellars, W.J. Tegart, Int. Mater. Rev. 17, 1-24 (1972).

[19] J. Szala, Computer Program Quantitative Metallography, MET-ILO v. 3.0, Silesian University of Technology (1997).

[20] J. Cwajna, M. Maliński, J. Szala, Mater. Eng. 14 (4), 79-88 (1993) (in Polish). 